\title{
ETANOL DE PRIMEIRA OU DE SEGUNDA GERAÇÃO? UMA COMPARAÇÃO ENTRE OS CICLOS PRODUTIVOS
}

\author{
Pedro Pinho Senna ${ }^{1}$ \\ Stela Luiza de Mattos Ansanelli (orientador) ${ }^{2}$
}

\section{Resumo}

O objetivo deste trabalho é investigar e comparar os ciclos produtivos do Etanol de $1^{\text {a }}$ Geração (E1G) e do Etanol de $2^{\mathrm{a}}$ Geração (E2G), em termos econômicos, tecnológicos, ambientais e sociais no Brasil, por meio de revisão bibliográfica e entrevista com especialista. O E1G apresentou vantagens econômicas e ambientais com relação aos combustíveis fósseis, mas, apesar dos avanços na mecanização da fase agrícola e do aumento do nível de escolaridade e formalidade dos trabalhadores, ainda está distante de setores não agrícolas. $\mathrm{O}$ E2G, em comparação com o E1G, demonstrou ganhos ambientais e sociais significativos, por ser produzido a partir de resíduos, usar menor quantidade de recursos naturais e energia, bem como utilizar mão de oba bastante qualificada envolvida em uma tecnologia mais complexa. Contudo, os custos econômicos e os investimentos são superiores aos do E1G. O ciclo integrado constitui uma forma de superar esses desafios por parte das usinas.

Palavras-chave: Etanol, Primeira Geração, Segunda Geração, Brasil.

\begin{abstract}
The purpose of this research is to investigate and compare both First Generation Ethanol (FGE) and Second Generation Ethanol (SGE) life-cycles, under economical, technological, environmental and social aspects in Brazil, by means of literature review and expert interview. FSE demonstrated both economic and environmental advantages in contrast with fossil fuels; however, in spite of developments in mechanization aimed at the agriculture stage and the recent growth of schooling levels, FSE still stands far from non-agricultural industries. SGE indicates significant environmental and social advantages, correlated to FSE, due to its decreased use of natural resources and energy, its feedstock being FSE solid residue, and the increase in technology with better qualified labor. The FSE-SGE combinedcycle is a viable proposition to overcome these challenges on behalf of the sugarcane plants.
\end{abstract}

Key-words: Ethanol, First Generation, Second Generation, Brazil.

\section{JEL O13; Q42}

\footnotetext{
${ }^{1}$ Graduando em Economia - UNESP

${ }^{2}$ Professora Dra. do Departamento de Economia da UNESP
} 


\section{Introdução}

O etanol é um combustível alternativo ao de origem fóssil, sendo considerado, portanto, como uma fonte renovável de energia. Este tem apresentado um mercado crescente, competitivo e de baixos impactos ambientais. Em 2007 a produção mundial de etanol foi da ordem de 55,7 bilhões de litros, tendo como líderes os Estados Unidos (EUA), por meio do etanol de milho, e o Brasil, com etanol de cana-de-açúcar. Contudo, o brasileiro é mais competitivo, visto que seu custo de produção tem sido de US\$ 0,22/litro contra US\$ 0,35/litro dos EUA (PACHECO, 2011).

Internamente a produção do etanol brasileiro tem crescido sobremaneira, passando de 22 bilhões de litros na safra de 2011/2012 para cerca de 30 bilhões na de 2015/2016 auxiliado pelos consumos internos do etanol anidro e do etanol hidratado. Com relação às outras culturas para produção de bioetanol, o de cana apresenta os melhores índices de produtividade: cerca de 9 mil litros por hectare (incluindo o etanol de biomassa), contra 2 mil litros por hectare do trigo e 4 mil do milho (MAPA, 2016).

Dentre os fatores estimulantes do setor, destacam-se as legislações ambientais que obrigam o uso de biocombustíveis em meios de transporte (em cumprimento às exigências do Protocolo de Kyoto), à mistura do biocombustível na gasolina e à disponibilização crescente de automóveis bicombustíveis (PACHECO, 2011). A Lei 13.033, por exemplo, sancionada em setembro de 2014, estabelece que o Poder Executivo poderá elevar de 25\% para 27,5\% o percentual obrigatório de adição de etanol anidro à gasolina, dada a viabilidade técnica (MILANEZ et al., 2015).

Por ter sido produzido desde os anos 1970, por conta do Programa Nacional do Álcool, o etanol brasileiro tem a vantagem de apresentar uma trajetória estabelecida. O processo tecnológico de produção do etanol, a partir do caldo resultante da moagem da canade-açúcar, é chamado de Etanol de Primeira Geração (E1G) (ABARCA, 2005).

Outra fonte para aumento da oferta do etanol pelo Brasil é a geração do produto por outros meios. O modo de produção do etanol, juntamente com o de açúcar, gera resíduos como palha e bagaço, que podem ser reaproveitados na forma de geração de energia elétrica e de mais etanol. Este último, etanol produzido a partir da biomassa da cana-de-açúcar ou Etanol de Segunda Geração (E2G), vem sendo desenvolvido desde 2010 no Brasil de forma

sistêmica, envolvendo o Governo, firmas privadas nacionais e estrangeiras e instituições de pesquisa. Estima-se que no longo prazo seja possível realizar uma produção de E2G de 350 milhões de litros por ano e com queda significativa do custo de produção em torno de $60 \%$ (MILANEZ, et al., 2015; ANSANELLI, et al., 2016). 
Por possibilitar ganhos de produtividade de extração de etanol por tonelada de cana processada, ao mesmo tempo em que permite melhor utilização dos resíduos provenientes do tratamento da cana-de-açúcar, gerando menor impacto ambiental, o E2G pode ser considerado uma inovação tecnológica ambiental (ANSANELLI, et al., 2016).

No entanto o modo de produção e os impactos do E2G apresentam algumas especificidades com relação ao E1G, pois é um processo novo, que exige maior intensidade de conhecimento e é realizado a partir de procedimentos químicos complexos. Portanto, o objetivo deste trabalho é investigar e comparar os ciclos-produtivos do E1G e do E2G em seus aspectos econômicos, tecnológicos e socioambientais. Serão eles substitutos ou complementares? Para tanto esse trabalho se divide em cinco seções, além dessa introdução. Numa primeira, (seção 1) serão apresentadas as oportunidades econômicas para o etanol brasileiro. Após a metodologia (seção 2), demonstram-se os ciclos produtivos e os aspectos econômicos, tecnológicos, ambientais e sociais do E1G (seção 3), do E2G (seção 4) e do ciclo integrado (seção 5). Uma síntese desta comparação e sugestões de pesquisas encontram-se na conclusão.

\section{O mercado do Etanol e oportunidades de crescimento para o Brasil}

Fatores econômicos e políticos vêm potencializando o mercado de etanol e gerando oportunidades para o Brasil. O início dos anos 2000 viu um forte avanço das potências mundiais, lideradas especialmente pelos Estados Unidos da América, em favor da substituição das bases de suas matrizes energéticas, atualmente centradas em combustíveis fósseis, por alternativas focadas em energias renováveis. A liderança americana se deu por conta do domínio da tecnologia de extração de etanol a partir do milho, recebendo maior importância após os abalos políticos que envolveram os países líderes e países do Oriente Árabe, mais notadamente Iraque e Afeganistão, onde os conflitos entre as nações levaram a solavancos no comércio do petróleo mundial (CGEE, 2008).

No Brasil, as iniciativas governamentais e privadas nos setores sucroalcooleiro e automobilístico conduziram à criação do motor flex-fuel, bicombustível, implementado com muito sucesso na indústria nacional e responsável pela aceleração do mercado nacional de etanol. Entre 2003 e 2007 a demanda nacional por etanol hidratado aumentou 273,36\%, passando de $3.792 \mathrm{mil} \mathrm{m}^{3}$ em 2003 para $10.366 \mathrm{mil} \mathrm{m}^{3}$ em 2007, o que demonstra o crescimento expressivo do setor, aliado à implantação do motor flex-fuel no mercado nacional, que em 2008 já superava 90\% dos motores da produção automobilística leve nacional (EPE, 2008; IICA, 2008). 
Embora tenha apresentado desempenho instável nas exportações recentemente, decaindo 39,91\% em volume e 59,72\% em dólares entre 2012 e 2015, a produção de etanol nacional teve crescimento significativo de $27,17 \%$, partindo de $22.736 .540 \mathrm{~m}^{3}$ na safra 2011/2012 para 28.916.281 $\mathrm{m}^{3}$ na safra 2014/2015, conforme Tabela 1. Isto foi motivado por um fator externo ocorrido no ano de 2011, quando o Congresso dos Estados Unidos da América revogou a taxação de impostos que incidem sobre o etanol brasileiro, além de suspender o subsídio aos produtores locais (PETROBRAS, 2011; UDOP, 2016).

Tabela 1. Produção Brasileira do Etanol $\left(\mathrm{em} \mathrm{m}^{3}\right)$

\begin{tabular}{c|c|c|c|c|c}
\hline & \multicolumn{5}{|c}{ Ano-Safra } \\
\hline Regiões & $11 / 12$ & $12 / 13$ & $13 / 14$ & $14 / 15$ & $15 / 16^{*}$ \\
\hline Norte/Nordeste & 2.139 .206 & 1.864 .442 & 1.966 .334 & 2.250 .777 & 1.641 .412 \\
Centro/Sul & 20.597 .334 & 21.608 .912 & 26.045 .950 & 26.665 .504 & 27.346 .352 \\
Brasil & 22.736 .540 & 23.473 .354 & 28.012 .254 & 28.916 .281 & 28.987 .764 \\
\hline
\end{tabular}

(*) Valores atualizados em 01/03/2016

Fonte: DCAA/SPAE/MAPA

Além dos americanos, o Japão tem se mostrado como um mercado em potencial, uma vez que as estratégias do país envolvem adicionar um volume extra de $10 \%$ de etanol à gasolina consumida no território. Este fato, aliado às condições geográficas do arquipélago japonês, o torna um excelente candidato para o escoamento da produção brasileira de etanol e para incremento nos níveis de exportação da commodity nacional. O cenário europeu também tem se mostrado favorável ao etanol brasileiro, uma vez que a mistura de 5,75\% de etanol à gasolina deve chegar a $10 \%$ em 2020. Como a beterraba é um produto considerado base da alimentação em vários países no velho continente, a extração de etanol a partir desse insumo em grande escala industrial pode representar um perigo para o abastecimento de alimentos da região, algo que pode fortalecer uma motivação para facilitar o comércio do etanol brasileiro produzido a partir da cana-de-açúcar (ARAÚJO et al., 2013).

O cenário energético constitui outro fator importante. Durante o ano de 2007, 46,8\% da energia consumida no Brasil foi proveniente de fontes renováveis, das quais o etanol é parte importante, enquanto que a média mundial ficou em 14\% (BALANÇO ENERGÉTICO NACIONAL, 2010). Outro elemento interessante é o custo de produção do etanol brasileiro produzido a partir da cana-de-açúcar que é US\$ 0,22/litro, 37,14\% menor do que o custo de produção do etanol americano a base de milho de US\$ 0,35/litros (VIEGAS, 2010). Em termos globais, o etanol representa atualmente mais de $90 \%$ do fornecimento de biocombustíveis líquidos (FAO, 2009).

Uma vantagem brasileira neste cenário é a longa trajetória de produção e exposição no cenário externo. Desde os anos 1970, com o Programa Nacional do Álcool, ocorreram avanços do setor sucroalcooleiro, pois a capacidade de moagem atingiu 100\%, o processo de 
extração passou de $93 \%$ para atingir $97 \%$, o de fermentação saltou de $80 \%$ para $91 \%$ e a recuperação geral na produção aumentou em 30\%, considerando-se o período 1975-1994. Isso se deu graças à implementação de inovações incrementais, instalação e melhoria de equipamentos periféricos, bem como a adoção de novos procedimentos operativos (ABARCA, 2005).

No que tange à questão da disputa entre combustível e alimento, vale ressaltar que a produção de cana-de-açúcar nacional ocupa mais de $2 \%$ das terras agricultáveis. Dos 63 milhões de hectares dos quais a lavoura nacional se utiliza, 7 milhões são dedicados à cultura da cana-de-açúcar, sendo metade dela (3,5 milhões) se destina à fabricação de etanol combustível (SCHUTTE, 2010). Além disso, a eficiência energética do etanol no Brasil, que possui um balanço energético de 10,2, é muito superior àquela do etanol de milho americano, cujo balanço energético aponta para 1,4, o que abre a possibilidade para um aumento de produtividade sem necessariamente requisitar um aumento de terras cultivadas, no âmbito brasileiro, caracterizando vantagem ímpar no mercado sucroalcooleiro mundial (GOLDENBERG, 2009).

Neste mercado, o aumento da oferta de etanol, proporcionado pelo E2G, apresenta oportunidades significativas para o setor sucroalcooleiro nacional de forma sustentável. Porém os ciclos produtivos, bem como os aspectos econômicos, tecnológicos, ambientais e sociais do E1G e do E2G apresentam diferenças.

\section{Metodologia}

Foi realizada uma extensa revisão bibliográfica, com ênfase em materiais recentemente publicados e divulgados (artigos de periódicos nacionais e internacionais, relatórios, sites e livros). Além disso, o trabalho contou com entrevista com o especialista Alexandre Enrico Figliolino, sócio da MB Agro.

\section{O ciclo produtivo do Etanol de Primeira Geração (E1G)}

O ciclo produtivo do etanol de primeira geração (E1G) tem início na Fase Agrícola e engloba o plantio, o cultivo e a colheita da cana-de-açúcar que será usada como insumo para os próximos estágios de produção. Existem atualmente duas formas de colheita da cana-deaçúcar, mecânica ou manual, e com a presença ou não da prática de queimada da cana no campo. Dessa forma, a cana-de-açúcar pode ser classificada por sua chegada à usina conforme a porcentagem de impurezas presentes no material vegetal, sendo a "Cana limpa" (concentração de impurezas $<0.6 \%$ ) considerada a mais adequada para a produção de etanol por conta da baixa presença de impurezas (ALBARELLI, 2013). 
A cana colhida durante a Fase Agrícola pode ser encaminhada para três principais tipos de plantas produtoras: as usinas produtoras de açúcar; destilarias autônomas com produção exclusiva de etanol e usinas integradas para produção conjunta de açúcar e etanol (ALBARELLI, 2013). Para os objetivos deste trabalho serão consideradas apenas as unidades produtoras de etanol (destilarias autônomas e usinas integradas) ${ }^{3}$.

A Fase Industrial do E1G, ilustrada pela Figura 1, é composta pela limpeza, extração e tratamento físico da cana de açúcar. Por conta do tipo de cultivo utilizado durante a Fase Agrícola (colheita mecânica ou manual, presença ou não de queimadas, condições climáticas e variedade de cana de açúcar), a composição média da cana de açúcar será de: água (70\%$76 \%$ da massa de cana), sólidos presentes - excluindo as fibras (10\%-16\%) - e fibras (11\%$16 \%)$.

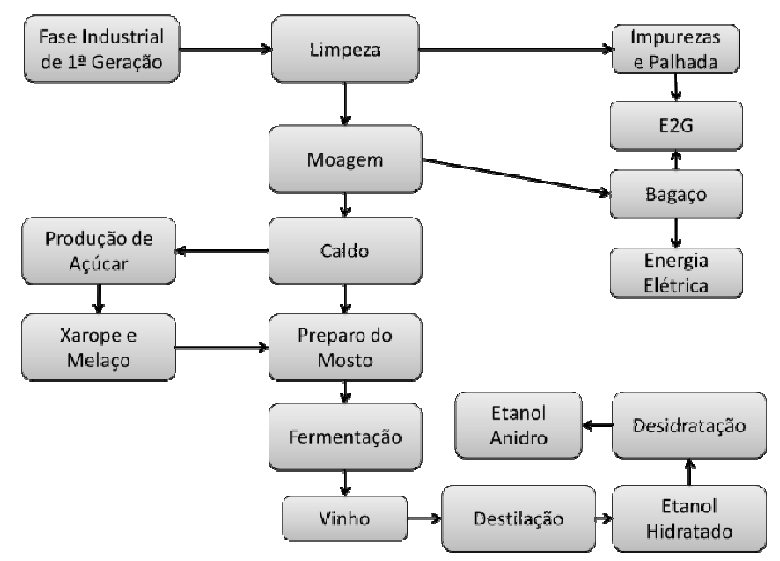

Figura 1. Fase Industrial do E1G Fonte: ALBARELLI (2013)

Após a limpeza, que pode ser a seco ou com utilização de água, a cana-de-açúcar é picada e encaminhada para a fase de moagem, na qual é extraído o caldo que será utilizado na produção de açúcar e etanol e gerado o bagaço. A produção de açúcar e de etanol apresentam processos distintos para o tratamento do caldo proveniente da extração. O caldo, depois de clarificado, é reservado para produção de açúcar e concentrado via evaporação, resultando num xarope de alta concentração de glicose. Parte deste xarope é misturada ao caldo clarificado e ao melaço, (mosto), que pode passar novamente por um processo de concentração por evaporação, para atingir o nível desejado para a fermentação. $O$ vinho proveniente da fermentação é então encaminhado para a etapa final de destilação, na qual se obtém etanol hidratado. Para a produção de etanol anidro, basta que o etanol hidratado passe por um processo de desidratação (HAMERSKI, 2009; USINA ESTER, 2016).

3 Existem atualmente 372 unidades de produção registradas e em atividade, com produção integrada de 41.453.194 $\mathrm{m}^{3}$ de etanol hidratado ao ano e 22.123.551 $\mathrm{m}^{3}$ de etanol anidro ao ano (EPE, 2016). 


\subsection{Aspectos econômicos, tecnológicos, ambientais e sociais do E1G}

Em termos econômicos, a produção de etanol no Brasil tem crescido sobremaneira, demonstrando um acréscimo de 35\% entre 2011 e 2016, devido à demanda (carros flex fuels ocupam $67 \%$ da frota nacional em circulação), o aumento da porcentagem de etanol anidro na gasolina de $25 \%$ para $27 \%$ e o aumento do preço final da gasolina, pela elevação no PIS/COFINS para a gasolina. No entanto, as usinas vêm se encontrando reféns do preço do açúcar, concorrente direto do etanol. Vale ressaltar que a produtividade e a qualidade da canade-açúcar estão sujeitas a diversos fatores como: eventos climáticos adversos (secas e estiagens fora de época) e a harmonização entre os processos de mecanização de plantio e de colheiro, que exigem cuidados especiais por se tratar de cultura sazonal. Com relação aos custos, $70 \%$ se concentram na fase agrícola, etapa esta que tem experimentado avanço tecnológico por conta da mecanização (DATAGRO, 2015; EPE, 2016; FIGLIOLINO, 2016).

No que se refere às características ambientais, frente aos combustíveis substitutos e fósseis, o E1G tem diversas vantagens, por apresentar: pequena área para cultivo (menos de $1 \%$ das terras cultiváveis nacionais); baixa perda de solo (62\% comparada ao observado na cultura de soja); queda na captação de água pelas usinas (de $5 \mathrm{~m}^{3} /$ ton de cana processada no início da década de 1990 para 1,8 m³/ton de cana em 2005); aumento na taxa média de reutilização de água (de 62,7\% na década de 1990 para 87.8\% em 2005); e redução na emissão de Gases de Efeito Estufa (GEE) (foram evitadas 2,7 milhões de toneladas de GEE em 2015) (UNICA, 2011; LEITE, 2008; CCGE, 2008).

Do ponto de vista social, apesar do setor ser intensivo em mão de obra, especialmente durante a Fase Agrícola, têm demonstrado elementos negativos e positivos. Houve um aumento dos empregados formais no pico da colheita (de 1,3\% do total nacional em 2014 para $2 \%$ ), contudo, ainda é significativo o nível de informalidade, representando $7 \%$ do total. Além disso, a maioria dos trabalhadores (57,2\% de um total aproximado de 385 mil empregados) estava lotada na produção de cana-de-açúcar, contra 34,2\% na indústria açucareira e 8,6\% na indústria do etanol, no ano de 2005. Também ocorreu queda do número de empregados devido à mecanização, mas foram criadas vagas de tratoristas, motoristas, mecânicos, condutores de colheitadores e técnicos em eletrônica. A renda média dos trabalhadores (chefe de família) é $46 \%$ maior do que em outros setores agrícolas, contudo é inferior à média nacional. Já quanto ao nível de escolaridade, houve aumento: 5 anos de escolaridade no setor contra 4 de outros setores agrícolas. (MTE, 2016; EPE, 2016; MORAES, 2007).

\section{Ciclo produtivo do E2G}


O E2G é produzido a partir do material lignocelulósico (MLC), que é um resíduo do ciclo produtivo de primeira geração proveniente de biomassa. Em média cada tonelada de cana-de-açúcar processada gera $280 \mathrm{~kg}$ de bagaço com $50 \%$ de umidade, tendo nas fibras o principal substrato para a produção do E2G. Desse modo, o ciclo produtivo do E2G se inicia na fase de resíduos do ciclo-produtivo do E1G, conforme Figura 2. Após chegada da biomassa à usina começa a fase de pré-tratamento, que pode ser por ácido diluído, explosão a vapor e hidrogênio alcalino. O produto sólido da fase de pré-tratamento (bagaço pré-tratado) passa pela hidrólise enzimática ou acídica, depois pela fermentação e destilação, gerando o etanol líquido (COSTA, 2014; STUCCHI, 2016).

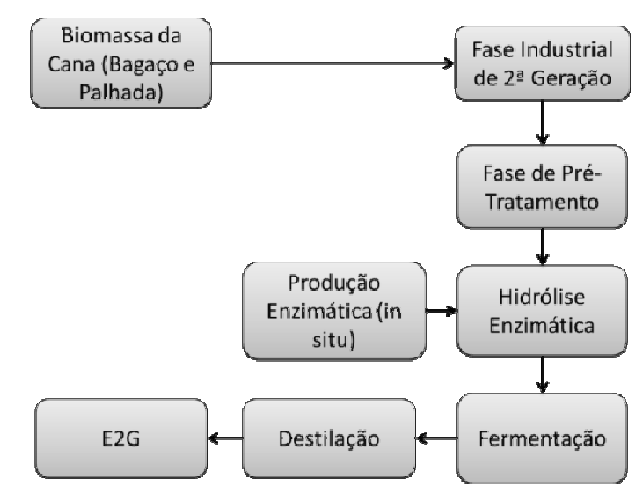

Figura 2. Fase Industrial do E2G. Fonte: COSTA (2014).

\subsection{Aspectos econômicos, tecnológicos, ambientais e sociais do E2G}

O E2G da cana apresenta as mesmas características, em termos de produto final, do E1G e desfruta, portanto, das mesmas vantagens do mercado em ascensão e da demanda. No entanto, o E2G tem custos produtivos diferenciados: o custo do E2G da cana é um pouco maior do que o do E1G ( $\mathrm{R} \$ 0,26^{4}$ por litro do E2G contra $\mathrm{R} \$ 0,22$ litro do $\left.\mathrm{E} 1 \mathrm{G}\right)$, mas o custo de capital do E2G da cana foi bastante inferior a outros tipos de biomassa (US\$ 100 milhões contra mais de US\$ 200 milhos do E2G dos resíduos de milho e trigo) (STUCCHI, 2016).

Em termos tecnológicos, o E2G se mostra especifico em comparação com a produção do E1G. Após a fase de pré-tratamento, há diferentes possibilidades tecnológicas, identificadas pela hidrólise ácida ou enzimática. A primeira representa uma tecnologia estabelecida, com menores riscos financeiros, enquanto a segunda reflete uma tecnologia mais complexa, que envolve maior incerteza nos investimentos, mas elevada possibilidade em termos de rentabilidade e redução de custos. Assim, há geração e desenvolvimento de

\footnotetext{
${ }^{4}$ Conforme dados da empresa Raízen.
} 
inovações no E2G em evolução com potenciais de ganhos econômicos (ALBARELLI, 2013; COSTA, 2014).

Com relação aos aspectos ambientais, o E2G tem apresentado impactos ambientais expressivamente menores do que os combustíveis fósseis e outros substitutos. Por ser produzido a partir de resíduos da cana, o E2G pode reduzir os danos ambientais de $85 \%$ a 90\% em comparação com o E1G. Na fase de pré-tratamento, o licor pode ser usado na produção de biogás, o que, juntamente com outros processos, permitiria uma recuperação energética de $63 \%$ a $65 \%$. Além disso, o bagaço pode ser utilizado tanto para a produção do etanol $(51 \%)$ quanto para a geração de energia (44\%), de modo que as usinas podem ser autossuficientes em termos energéticos. O consumo da água na produção do E2G representou $45 \%$ do consumo total e o índice de reuso foi de 84\% (MILANEZ et al, 2015; MOREIRA et al, 2014; ALBARELLI, 2013).

Do ponto de vista social, há uma necessidade de maior quantidade de mão de obra especializada dentro do $\mathrm{E} 2 \mathrm{G}$ do que no $\mathrm{E} 1 \mathrm{G}$, dada as novas tecnologias envolvidas. A conversão dos resíduos celulósicos em etanol, por exemplo, é fortemente dependente da temperatura, demonstrando a necessidade de mão de obra altamente qualificada para garantir controle de qualidade durante a condução dos processos. Com relação à renda, observou-se uma correlação positiva com o nível de escolaridade e pode apresentar variações de $400 \%$ entre os postos de trabalho (MOREIRA et al, 2014; BNDES, 2014).

\section{Integração E1G/E2G}

A introdução do paradigma tecnológico do E2G ao E1G, conforme representado pela Figura 3, traria maiores vantagens econômicas, ambientais e sociais do que a produção exclusiva do E1G ou do E2G. A produtividade poderia aumentar de 31\% a 75\% com relação ao nível atual, bem como diminuir 50\% dos custos referentes ao processo do E2G e $90 \%$ dos custos totais. Poderiam ser reduzidos os custos de transporte de material celulósico, permitindo o uso de equipamentos comuns de forma simultânea (ALBARELLI, 2013; DIAS, 2011).

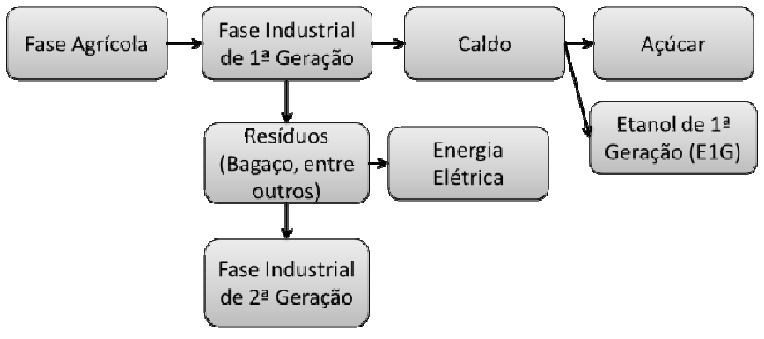

Figura 3. Ciclo produtivo integrado E1G/E2G. 
Fonte: ALBARELLI (2013).

Algumas projeções demonstram outros benefícios financeiros: quedas de $10 \%$ dos custos de investimento, do capital de giro e do custo anualizado de investimento; acréscimos de $41,49 \%$ na receita, de $148,43 \%$ do potencial econômico e $1402,43 \%$, do valor presente líquido (VPL).

Em longo prazo seria possível realizar uma produção de E2G de 350 milhões de litros/ano com investimento anual próximo de $\mathrm{R} \$ 300$ milhões, o que oferecia a possibilidade de redução nos custos de produção. Nesse cenário o E2G pode se tornar mais competitivo, integrado ao $\mathrm{E} 1 \mathrm{G}$, frente à gasolina e demais combustíveis fósseis, especialmente no longo prazo (CGEE, 2009; MILANEZ et al, 2015; ANDRADE, 2012; COSTA, 2014; ALBARELLI, 2013).

Em termos ambientais, a integração do E2G ao processo já desenvolvido nas usinas de E1G conferiu melhorias na diminuição do consumo de água em 13,59\%, aumento de 8,85\% no reuso da água e corte de $53,24 \%$ da captação de água para todo o processo produtivo. Além disso, a utilização de água exclusivamente para os processos do $\mathrm{E} 2 \mathrm{G}$ caem 77,52\% em usinas integradas. Além disso, o uso do bagaço como matéria-prima nos processos de $2^{\mathrm{a}}$ Geração permitiu um aumento de $19 \%$ da produção de etanol e de $40 \%$ a $70 \%$ da eletricidade disponível nas usinas autônomas (ALBARELLI, 2013).

No que tange os aspectos sociais, a integração do E2G tem potencial de contribuir para a diminuição do trabalho infantil na lavoura, aumento da formalização e nível de escolaridade (embora ainda seja baixa, mas já apresentou evolução) (MORAES et al, 2015).

Contudo, por ser uma tecnologia incipiente, especialmente no que tange a algumas modalidades de pré-tratamento, o E2G ainda requer altos investimentos em Pesquisa e Desenvolvimento $(\mathrm{P} \& \mathrm{D})$ para encontrar viabilidade em escala comercial.

Estes fatores demonstram que o E2G, integrado ao processo pré-existente do E1G, pode ser uma alternativa para países que desejam elevar os níveis de produção de etanol sem aumentar a área de cultivo, sendo, portanto, complementar à produção de alimentos e de baixo impacto ambiental.

\section{Conclusões}

O objetivo deste trabalho foi comparar os ciclos produtivos do E1G e do E2G, em seus aspectos econômicos, tecnológicos, ambientais e sociais no Brasil, por meio de revisão bibliográfica e entrevista com especialista. Observou-se que há um mercado em ascensão para o etanol, seja de primeira ou segunda geração, visto que o produto final é o mesmo e não se 
estabelece concorrência. Quanto ao processo produtivo, o E1G apresentou uma tecnologia madura e vantagens econômicas e ambientais frente aos combustíveis fósseis. Na fase agrícola, vem utilizando mecanização e, apesar do aumento do nível de escolaridade, ainda há significativa participação de mão de obra desqualificada e informal.

O E2G ainda tem custos um pouco acima do E1G, mas o avanço tecnológico no médio longo prazo permite ganhos potenciais de rentabilidade e produtividade exigindo elevados investimentos em P\&D. No entanto os benefícios ambientais são bastante superiores, se comparados aos dos combustíveis fósseis e a outros substitutos renováveis. Um fator que merece destaque é a qualificação da mão de obra bem mais elevada do que na produção do E1G. O ciclo integrado, por sua vez, permitiria superar os desafios de escolher entre uma produção e outra, no que se refere aos quatro aspectos investigados, mostrando ser a melhor opção para usinas do setor. O Quadro 1 a seguir sintetiza essas evidências.

Dessa forma, a principal conclusão do estudo mostra que os ciclos são complementares, e não substitutos. Algumas lacunas identificadas no estudo iluminam pesquisas futuras, como investigar o tipo de emprego criado, as políticas voltadas ao setor e as atividades inovativas envolvidas nos ciclos produtivos do E1G, E2G e ciclo integrado.

Quadro 1. Síntese de comparação entre os ciclos produtivos do E1G e do E2G

\begin{tabular}{|c|c|c|c|}
\hline $\begin{array}{l}\text { Aspectos / } \\
\text { Geração }\end{array}$ & E1G (cana-de-açúcar) & $\begin{array}{l}\text { E2G (resíduo da cana-de- } \\
\text { açúcar) }\end{array}$ & E1G/E2G (Ciclo Integrado) \\
\hline Econômicos & $\begin{array}{l}\text { Preço mais competitivo frente à } \\
\text { gasolina } \\
\text { Custos concentrados na Fase } \\
\text { Agrícola }(70 \%) \\
\text { Porcentagem de Etanol Anidro } \\
\text { na Gasolina: } 25 \%->27 \% \\
\text { Alterações na CIDE para } \\
\text { gasolina } \\
\text { Veículos flex-fuels: maioria da } \\
\text { frota nacional }\end{array}$ & $\begin{array}{l}\text { Custo produtivo maior do que } \\
\text { do E1G } \\
\text { Preço Mínimo de Venda médio } \\
\text { menor (comp. outras fontes) } \\
\text { Produtividade média maior } \\
\text { (comp. outras fontes) } \\
\text { Custo de Capital médio inferior } \\
\text { (comp. Outras fontes) }\end{array}$ & $\begin{array}{l}\text { Ciclo produtivo de fácil } \\
\text { integração } \\
\text { Diminuição de Custos (de até } \\
90 \% \text { ) } \\
\text { Melhores indicadores } \\
\text { financeiros } \\
\text { (aumento da receita, potencial } \\
\text { econômico e VPL) } \\
\text { Ganhos de produtividade }\end{array}$ \\
\hline Tecnológicos & $\begin{array}{l}\text { Cultura mecanizada } \\
\text { Mão-de-obra com baixo-médio } \\
\text { nível de escolaridade } \\
\text { Presença de tecnologia intensiva } \\
\text { em capital } \\
\text { Alta produtividade por área } \\
\text { plantada }\end{array}$ & $\begin{array}{l}\text { Indústria altamente tecnológica } \\
\text { Mão-de-obra com alto nivel de } \\
\text { escolaridade } \\
\text { Inovação Brasileira (E2G- } \\
\text { bagaço) } \\
\text { Diferencial entre firmas: fase de } \\
\text { pré-tratamento }\end{array}$ & $\begin{array}{l}\text { Melhoria dos processos } \\
\text { conjuntos (Fase Agrícola) } \\
\text { Maior disponibilidade para } \\
\text { cogeração (açúcar e energia } \\
\text { elétrica) }\end{array}$ \\
\hline Ambientais & $\begin{array}{l}\text { Menor uso do solo } \\
\text { Emissão CO2 } 90 \% \text { menor } \\
\text { comparado à gasolina }\end{array}$ & $\begin{array}{l}\text { Inovação Ambiental } \\
\text { Diminuição dos impactos } \\
\text { ambientais E1G }\end{array}$ & $\begin{array}{l}\text { Redução do consumo de água e } \\
\text { da captação de água } \\
\text { Maior reuso da água e da } \\
\text { disponibilidade da energia } \\
\text { elétrica }\end{array}$ \\
\hline Sociais & $\begin{array}{l}\text { Média de renda e escolaridade } \\
\text { maior comparado à } \\
\text { trabalhadores do setor agrícola }\end{array}$ & $\begin{array}{l}\text { Melhoria da qualificação de } \\
\text { mão-de-obra } \\
\text { Mão-de-obra com nível de } \\
\text { renda e escolaridade mais } \\
\text { elevados }\end{array}$ & $\begin{array}{l}\text { Potencial de inclusão social } \\
\text { através de mão de obra } \\
\text { qualificada, do nível do nível de } \\
\text { renda médio comparado à } \\
\text { trabalhadores setor agrícola }\end{array}$ \\
\hline
\end{tabular}

Fonte: elaboração própria 


\section{Referências}

ALBARELli, J. Q. Produção de Açúcar e Etanol de Primeira e Segunda Geração: Simulação, Integração Energética e Análise Econômic. 2013. F. Dissertação (Doutorado) Faculdade de Engenharia Química, Universidade Estadual de Campinas, Campinas, SP, 2013.

ANSANELli, S. L. M.; SENNA, P. P.; RIBEIRO, G.; CAMPOS, D. A. C. Sistemas de inovação ambiental em países em desenvolvimento: uma discussão a partir do desenvolvimento do etanol de segunda geração no Brasil. In: Anais do XXI Encontro Nacional de Economia Política. UFABC - São Bernardo do Campo, junho de 2016.

BNDES/FEP. Estudo de Viabilidade de Produção de Biocombustíveis na UEMOA (União Econômica e Monetária do Oeste Africano). Chamada Pública de Prospecção para Relatórios 4 e 5 FEP. Rio de Janeiro: BNDES, janeiro de 2014. Disponível em: http://www.bndes.gov.br/SiteBNDES/export/sites/default/bndes_pt/Galerias/Arquivos/produt os/download/aep fep/chamada publica FEP0211 Relatorios4e5.pdf Acesso em: Julho de 2016.

CENTRO DE GESTÃO E ESTUDOS ESTRATÉGICOS - CGEE. Bioetanol de cana de açúcar: energia para o desenvolvimento sustentável. BNDES e CGGE, Rio de Janeiro: BNDES, 2008.

COSTA, AC, Caso de Sucesso: Produção de Etanol (2 ${ }^{\mathbf{a}}$ Geração). Laboratório de Engenharia de Processos Fermentativos e Enzimáticos (LEPFE) - Faculdade de Engenharia Química, Universidade Estadual de Campinas, 2014.

DATAGRO. Estimativa da frota de veículos de ciclo Otto no Brasil. Relatório técnico. [S.I.]: [s.d.]. Disponível em:http://goo.gl/ydJkNo. Acesso em: 26 de Julho de 2016.

DIAS, M. O. S. Desenvolvimento e otimização de processos de produção de etanol de primeira e segunda geração e eletricidade a partir da cana-de-açúcar. 2011. 277 f. Tese (Doutorado) - Faculdade de Engenharia Química, Universidade Estadual de Campinas, Campinas, SP, 2011. 
Empresa de Pesquisa Energética - Ministério de Minas e Energia. Análise de Conjuntura dos Biocombustíveis - Ano 2015. Maio, 2016. Disponível em: <http://www.epe.gov.br/> Acesso em 15 de Julho de 2016.

FIGLiOLINO, A. E. (2016) Entrevista concedida para Tese de Conclusão de Curso Pedro Pinho Senna. São Paulo: Julho de 2016.

GHOSH, A.M.; BLAKRISHNAN, M. Pilot demonstration of sugarcane juice ultrafiltration in an Indian sugar factory. Journal of Food Engineering, v58, n.2, p.143150, June 2003.

HAMERSKI, F. Estudo de variáveis no processo de carbonatação do caldo de cana-deaçúcar.2009. 148 f. Dissertação (Mestrado) - Programa de Pós-Graduação em Tecnologia de Alimentos, Universidade Federal do Paraná, Curitiba, PR, 2009.

IPCC, 2006. Intergovernmental Panel on Climate Change. Disponível em http://www.ipccnggip.iges.or.jp/public/2006gl/vol2.html Acesso em 15 de Maio de 2016.

LEITE, H. T. C. Uso da água na produção de etanol de cana-de-açúcar. Projeto Programa de Pesquisa em Políticas Públicas. Campinas: Proamb Engenharia, 2008.

MILANEZ, A. Y. et al. De promessa a realidade: como o etanol celulósico pode revolucionar a indústria da cana-de-açúcar: uma avaliação do potencial competitivo e sugestões de política pública. BNDES Setorial, 41. Rio de Janeiro: BNDES, março de 2015.

MORAES, M. A. F. D.: O mercado de trabalho da agroindústria canavieira: desafios e oportunidades.Econ. Aplic., São Paulo. V. 11, n. 4, p 605-619, Out/Dez 2007. Disponível em: http://www.scielo.br/pdf/ecoa/v11n4/08.pdf. Acesso em 25 de Julho de 2016

MORAES, M. A. F. D.; OLIVEIRA, F. C. B.; DIAZ-CHAVEZ, R. A.; Socio-economic impacts of Brazilian sugarcane industry. Environmental Development. V.16, p.31-43. Dez, 2015. Disponível em: http://www.sciencedirect.com/science/article/pii/S2211464515000627 Acesso em 25 de Julho de 2016

MOREIRA, R. F.; Almeida, O.; MACHADO, N. T.; RODRIGUES, E.; Neto, A. M. J. C.; Cordeiro, M. A.; Chagas, B. R.; Teixeira, M. L. T.; Veiga da Silva, P. R.; Tenoro, E. L. G. Produção de Bioetanol a partir da hidrólise enzimática do bagaço de cana-de-açúcar. 
XX Congresso Brasileiro de Engenharia Química. Florianópolis: XX COBEQ, outubro de 2014 .

STUCCHI, A. A. Palestra: A experiência da Raízen com E2G e perspectivas para o

futuro. NovaCana Ethanol Conference 2016. Disponível em:

https://www.novacana.com/n/eventos/a-experiencia-da-raizen-com-o-etanol-de-segundageracao-130616/ Acesso em: Julho de 2016.

USINA ESTER. O Processo de fabricação de açúcar e álcool na Usina Ester. Disponível em: http://pt.slideshare.net/clamcle/o-processo-de-fabricao-de-acar-e-lcool-na-usina Acesso em: 01 de Junho de 2016. 